\title{
O TUTOR NA EDUCAÇÃO A DISTÂNCIA E REDES COLABORATIVAS DE APRENDIZAGEM
}

Márcia Aparecida Barbosa

Mestranda em Educação da Universidade Estadual Paulista - UNESP. E-mail: marciatashiro@gamil.com

\section{RESUMO}

O objetivo deste estudo é refletir sobre o papel do tutor na formação de uma rede de aprendizagem. Refletir sobre quem é esse profissional e quais suas atribuições, qual o perfil de aluno de um curso à distância e como o tutor poderá favorecer a formação desta rede. Por meio de uma pesquisa bibliográfica constatou-se que a formação de uma rede colaborativa de aprendizagem é uma alternativa à transmissão de informações, uma possibilidade de superação do paradigma de educação tradicional presente em cursos a distância. A função do tutor nesta proposta é de estimular os estudantes a aprender juntos, de maneira dinâmica; compartilhar experiências; participar ativamente das atividades e a colaborar com os demais membros da turma.

\section{INTRODUÇÃO}

O avanço das tecnologias da informação e da comunicação alterou a forma de produzir e transmitir informação e a Educação a Distância apresenta-se como alternativa que atende às diferentes necessidades de formação, superando os limites de espaço e tempo.

Uma pesquisa bibliográfica sobre o tutor de cursos a distância indica que a interação professor/aluno e aluno/aluno precisa ser fortalecida para que a aprendizagem se torne mais significativa. A formação de uma rede colaborativa de aprendizagem, neste contexto, mostra-se como uma possibilidade para o tutor estimular a participação dos membros da turma.

Este estudo objetivou analisar como o tutor pode, considerando suas atribuições e o perfil ideal de aluno desta modalidade, favorecer a formação da rede colaborativa de aprendizagem e contribuir para a melhoria da qualidade dos cursos EAD.

\section{OBJETIVO}

O objetivo deste estudo é refletir sobre o papel do tutor na formação de uma rede de colaborativa de aprendizagem, conhecer quem é esse profissional e quais atribuições, identificar o perfil ideal de aluno de cursos a distância. Além de compreender como o tutor poderá favorecer a formação desta rede. 


\section{METODOLOGIA}

Uma pesquisa bibliográfica possibilitou o conhecimento de estudos realizados sobre o tema em questão e indicou os caminhos que podem ser explorados.

\section{O TUTOR NA EDUCAÇÃO A DISTÂNCIA}

Muitos autores defendem uma atuação docente que considere as necessidades dos alunos e que construa mecanismos que favoreçam uma aprendizagem significativa. Para Patto (2010) o professor deve buscar as qualidades positivas de cada aluno com o objetivo de provocar seu desenvolvimento.

A educação a distância exige uma postura específica tanto do aluno quanto do professor. 0 professor de um curso a distância não é uma figura dispensável, muito pelo contrário, nesta modalidade, suas funções são mais abrangentes e com algumas características específicas. Ao se pensar em um curso de EAD de qualidade constata-se que o professor deve ser: produtor, pois deve ajudar e conhecer todo processo de elaboração e seleção dos conceitos do currículo do curso; parceiro de todos os envolvidos no planejamento do curso; mediador das relações, tanto entre os alunos como entre esses e o conhecimento; além de ser pesquisador, bom ouvinte e sensível.

O tutor na EAD é aquele que atua diretamente com os alunos, faz intervenções, propõe atividades, avalia, faz correções, pode unir ou separar o grupo. É um profissional que, pela própria característica de sua função, tem a possibilidade de utilizar diferentes recursos metodológicos no processo de ensino e aprendizagem.

Num curso a distância é muito fácil o aluno se sentir solitário. A sensação de pertencimento deve estar incutido no aluno desde o primeiro dia de aula. Ele deve se sentir dentro de um grupo, dentro de uma família; ser motivado de diferentes formas a participar e continuar o curso. Neste sentido, o papel do professor, denominado por muitos como tutor, envolve algumas atribuições que também são inerentes aos professores de cursos presenciais, porém com características distintas. Como acolher, motivar, acompanhar, orientar e avaliar (CORTELAZZO, 2009).

O ambiente de ensino a aprendizagem presencial conta com alguns fatores que podem potencializar o processo de educativo. As sensações permeiam todo o ambiente escolar. Os sons, os cheiros, as vozes, as mensagens, os gestos, as cores, as discussões, as brigas, a mistura de 
culturas, os tipos de personalidades, os diálogos, o toque, as amizades, o carinho, a frustração e outras formas de interação dão identidade a uma escola, a um espaço educativo formal.

O espaço presencial difere do espaço virtual. No virtual certas sensações nunca serão efetivadas, no entanto poderão ser compensadas por outras. É interessante que a motivação, o respeito pelo outro e pelo conhecimento, a vontade do compartilhar informações e experiências e a vontade de aprender junto sejam fortemente estimuladas. Isto posto, o diálogo é um meio muito propício para que esta missão seja cumprida. Maia e Mattar (2007, p.05) afirmam a importância do diálogo citando Paulo Freire:

O diálogo, segundo Freire, pressupõe o amor ao outro. Sem diálogo não há comunhão; sem comunhão não há educação. Educar (e se educado) é um ato de 'co-laborar: trabalhar em conjunto. Por isso, enquanto a educação bancária está associada à ideia de um programa, a educação problematizadora está associada à ideia de diálogo.

As especificidades de um curso a distância exigem dos tutores atitudes que, de acordo com a literatura estudada, ainda é pouco percebida. Na maioria dos cursos ofertados a proporção professor/aluno não é respeitada inviabilizando um bom atendimento e diminuindo as chances do curso ser de qualidade. Outro complicador em relação ao trabalho do tutor está relacionado à formação deste profissional. Na maioria dos casos é uma pessoa com formação diferente da área de atuação. Poucas opções de formação específicas foram encontradas na rede de computadores durante este estudo.

O despreparo do profissional que atua diretamente com o aluno é um fator que colabora para a evasão, favorecendo a desistência daqueles que esperam do tutor atitudes de companheirismo, apoio e orientação.

Um aluno da EAD, pensando em características ideais, deve ser autônomo, disciplinado, disposto a buscar respostas, arquiteto e construtor de seu conhecimento. Deve saber superar as dificuldades e interagir com seus pares.

Percebe-se a exigência de um perfil de aluno na EAD que não é comum à maioria dos alunos de hoje, portanto cabe ao professor ajudar a desenvolver tais atitudes e habilidades desses alunos. Um conhecimento acerca do processo de aprendizagem, de mecanismos de motivação entre outros, mostra-se indispensável. Assim como o tutor, todos os envolvidos no processo educativo devem estar em permanente aprendizado. Como afirma Kenski (2003, p.30):

As velozes transformações tecnológicas da atualidade impõem novos ritmos e dimensões à tarefa de ensinar e aprender. É preciso estar em permanente estado de aprendizagem e de adaptação ao novo. Não existe 
mais a possibilidade de considerar a pessoa totalmente formada, independentemente do grau de escolarização alcançado. Além disso, múltiplas são as agências que apresentam informações e conhecimentos a que se pode ter acesso, sem a obrigatoriedade de deslocamentos físicos até as instituições tradicionais de ensino para aprender.

Na superação da ideia de que na EAD tudo é mais fácil, rápido, pouco exigente, mecânico, superficial e sem qualidade, os tutores aparecem como principais agentes. Esses profissionais colaboram para a elevação da qualidade da Educação a Distância quando assumem atitudes de pesquisador, educador, agente social e quando são conscientes da importância de seu papel na sociedade. Também ao refletirem sobre o tipo de cidadão e de sociedade que pretendem, buscando identificar os objetivos da educação e as metodologias mais adequadas para alcançá-los.

\section{O TUTOR E REDES COLABORATIVAS DE APRENDIZAGEM}

No capítulo anterior vimos que o tutor é um agente de grande importância para a qualidade da educação a distância. A ele cabem algumas funções que podem nortear o processo de ensino e aprendizagem. Mas como este profissional pode atuar para que um curso a distância seja de qualidade? Quais atitudes, ações e recursos poderão ajudá-lo nesta empreitada?

Neste momento vale esclarecer que não nos referimos a uma ou outra modalidade de curso especificamente. Busca-se refletir sobre o papel do tutor de modo geral, pensando neste como o profissional que interage diretamente com os estudantes, porém é importante lembrar que as diferentes modalidades de cursos podem exigir mais ou menos do tutor.

Multiplicaram-se nos últimos anos as possibilidades de autoaprendizagem, aprendizagem aberta ou compartilhada. A Internet favorece a disseminação das informações e do conhecimento. Se o indivíduo percebe a necessidade de buscar capacitação e se interessa em saná-la, pode descobrir a grande variedade de cursos que são ofertados tanto em instituições cujos cursos exigem sua presença como na modalidade a distância.

A infinidade de instituições que ofertam cursos a distância é um determinante para a dificuldade de se acompanhar, avaliar e controlar a oferta e a qualidade. Os cursos de graduação é uma modalidade fiscalizada por órgãos oficiais que devem, por meio de representantes, fazer visitas in loco, avaliar os recursos materiais, a capacitação dos profissionais envolvidos no curso, a oferta de livros impressos e digitais, os acessos aos ambientes físicos e virtuais e demais fatores que podem interferir na qualidade do curso. Pesquisas apontam para a baixa qualidade dos cursos de graduação a distância de algumas instituições públicas e privadas do país. Ao apontar as 
deficiências da EAD neste estudo, não se pretende fazer generalizações, tão pouco desqualificá-la. O objetivo é buscar subsídios teóricos que possam contribuir para a reflexão sobre como melhorar sua qualidade.

Ao fazer um curso EAD é comum o aluno se sentir desmotivado e desistir do curso, mesmo que a conclusão do curso possa ser revertido em vantagens financeiras para ele. A evasão não é uma preocupação apenas dos cursos presenciais, porém na EAD ela é reforçada e aumenta a cada dia, devido às sensações de solidão, desamparo, isolamento e de não pertencimento a um grupo, a uma situação. O estudante precisa estar integrado, envolvido no processo; dialogar com seus pares, identificando a relevância dos conceitos aprendidos e participando ativamente das atividades propostas. Neste contexto as intervenções do tutor devem ser condizentes com o que se pretende alcançar, com os objetivos definidos no planejamento do curso. Os recursos materiais e as metodologias precisam acompanhar a dinâmica da turma, bem como estar relacionado ao contexto social e do ensino. Em relação à evasão Sales discorre em sua dissertação:

No estudo realizado por Walter (2006), alunos que possuíam comportamento e atitudes favoráveis a curso a distância foram os que menos evadiram. Esses fatores estavam relacionados à organização da agenda por parte dos alunos de forma a determinar horários específicos para realizar o curso a distância, a elaboração de um plano de estudo, a facilidade de realizar um curso, o sentimento favorável ao estudo individual, a leitura de materiais sobre as características do curso, conciliação dos estudos com atividades familiares e profissionais, sentimento de apoio pelo tutor, satisfação com as notas, incentivo da família e organização para a realização do curso e estímulo à participação das atividades em grupo. (2009, p. 65)

A autora continua, discorrendo:

Em contrapartida, os alunos que possuíam comportamentos e atitudes desfavoráveis foram os que mais evadiram. Esses fatores foram a falta de presença física de outros alunos, a falta de aulas presenciais, a falta de contato visual, a dificuldade do conteúdo do curso, a dificuldade de realizar o curso dentro do prazo e a dificuldade de utilização dos recursos tecnológicos de informática. (SALES, 2009, p. 65)

Os estudos de Sales (2009) apresentam diferentes variáveis que influenciam a desistência do curso por parte do aluno, entre elas estão às relacionadas à idade, habilidade com recursos tecnológicos, dificuldade financeira, medos de exames, outras experiências educacionais, falta de tempo. Esses estudos apontam a motivação pessoal com o curso como um fator que influencia na permanência no curso. Faria $(2002$, p.44) concorda com Sales quando diz que "o alto nível de 
motivação e o envolvimento de alunos e professores se constituem numa característica promissora da EAD".

Ser autônomo, disciplinado, pesquisador, participativo, criativo, flexível, crítico e colaborador é uma exigência da educação atual, no entanto na EAD tais características são mais valorizadas. Para estar em sintonia com as transformações da sociedade a educação deve desenvolver tais habilidades nos estudantes. Na EAD o tutor é o agente responsável por estimular o desenvolvimento deste perfil de aluno e pode por meio de metodologias adequadas, mantendose em constante contato com ele, incentivar sua permanência no curso.

A facilidade de se obter informações deveria ser um grande trunfo dos professores, porém muitos não conseguem mudar de paradigmas, ficando presos à transmissão de informações. Os estudantes de hoje percebem esta deficiência da Educação e a confirmam na medida em que ficam dispersos, desinteressados no ambiente escolar, seja ele presencial ou virtual. O aluno está inserido numa sociedade dinâmica, em que os recursos tecnológicos e interativos fazem parte do seu cotidiano. A educação tradicional não atende às necessidades atuais, ficando desatualizada, descontextualizada e desinteressante.

A Educação a Distância por meio da Internet tem muitas possibilidades a seu favor. Existem diferentes mídias que podem tornar a aula mais interessante, dinâmica e favorecer os diferentes modos de interação com os pares e com o conhecimento, alterando comportamentos. Para Kenski (2003, p. 33) “O estilo digital engendra, obrigatoriamente, não apenas o uso de novos equipamentos para a produção e a apreensão de conhecimento, mas também novos comportamentos de aprendizagem, novas racionalidades, novos estímulos perceptivos".

Se o isolamento, a individualidade, a solidão de um curso a distância afasta o estudante, parece certo afirmar que, salvo as particularidades de cada um, ele não terá motivo para desistir do curso se pertencer a um grupo, participar ativamente das atividades e decisões, colaborar e receber contribuições dos membros do grupo, ser sempre motivado e estimulado, tanto pelos colegas quanto pelo tutor.

Para Kenski (2003, p.112):

A criação de ambientes virtuais tecnologicamente apropriados para a realização de atividades educacionais precisa ser complementada com ações que tiram as pessoas do isolamento e as encaminhem para atividades em grupo, em que possam atuar de forma colaborativa. Com a colaboração de cada um para a realização de atividades de aprendizagem, formam-se laços e identidades sociais. Assim, criam-se grupos que, além dos conteúdos específicos, aprendem regras e formas de convivência e sociabilidade que persistem no plano virtual e fora dele. 
Enfim quando este estudante está integrado a uma rede de aprendizagem na qual pode aprender de modo colaborativo, junto com os colegas, num trabalho coletivo mediado pelo tutor, os resultados do processo podem ser muito mais promissores. Neste sentido a afirmação de Cortelazzo (2009, p.127) pode contribuir: “não é a tecnologia nem são as mídias que transformam uma interação em colaboração, mas a prática pedagógica de professores e alunos proativos se configura como colaboração se forem seguidas certas regras em torno do objetivo comum". E Kenski (2003, p.123) reforça esta ideia dizendo:

Interagir com as informações e com as pessoas para aprender é fundamental. Os dados encontrados livremente na Internet transformamse em informações pela ótica, pelo interesse e pela necessidade com que o usuário os acessa e os considera. Para a transformação das informações em conhecimentos é preciso um trabalho processual de interação, reflexão, discussão, crítica e ponderações que é mais facilmente conduzido quando partilhado com outras pessoas. As trocas entre colegas, os múltiplos posicionamentos diante das informações disponíveis, os debates e as análises críticas auxiliam a compreensão e a elaboração cognitiva do indivíduo e do grupo. As múltiplas interações e trocas comunicativas entre parceiros do ato de aprender possibilitam que esses conhecimentos sejam permanentemente reconstruídos e reelaborados.

A autora aborda a questão da interação e da construção coletiva do conhecimento. 0 tutor, neste contexto, será um agente que estimulará a formação deste grupo unido pelo mesmo objetivo: aprender. Este grupo constituirá, auxiliado pelo tutor, uma rede colaborativa de aprendizagem (CORTELAZZO, 2009).

Numa rede colaborativa a aprendizagem acontece de modo a integrar cada estudante no processo. Nela o tutor terá a tarefa de estimular o diálogo entre os membros do grupo, dialogando também como parceiro na busca e construção do conhecimento. É possível ao tutor se beneficiar dos diversos recursos que os variados AVAs - Ambientes Virtual de Aprendizagem oferecem, como fóruns, chats, e-mails, para favorecer trocas entre os membros do grupo. Conhecendo sua turma e cada aluno poderá, por meio de metodologias que atendam as especificidades e necessidades do grupo, intervir de maneira que contribua para a aprendizagem significativa. Para que os resultados dessas intervenções sejam positivos, além do exposto mostra-se essencial que o tutor não se baseie em conhecimentos vindos apenas de sua prática ou do senso comum, seu trabalho deve estar fundamentado em experiências e pesquisas sobre o assunto.

Com aprendizagem colaborativa organizada de forma que possibilite a integração e aproveitamento dos recursos midiáticos, os alunos poderão se comunicar com um ou com vários 
colegas ao mesmo tempo. Conhecer as produções escritas, sugerir, questionar, compartilhar material. Enfim, deve-se superar o isolamento e a individualidade característicos dos cursos a distância e favorecer o envolvimento e a integração de cada estudante no grupo.

\section{CONSIDERAÇÕES FINAIS}

A EAD é uma modalidade que possibilita formação de pessoas em lugares de difícil acesso, contribuindo para a inclusão social.

Os resultados deste estudo apontam para necessidade de se refletir sobre os rumos da educação a distância em nosso país, pois o paradigma de ensino vigente mostra-se deficiente, indicando a necessidade de se adotar metodologias de ensino que integrem o estudante ao grupo, estimulando sua participação ativa, questionadora e colaborativa, onde o tutor tem um papel essencial, atuando no sentido de favorecer a formação de uma rede colaborativa de aprendizagem.

O perfil de aluno de EAD apresenta algumas características primordiais, entre elas a autonomia e a disciplina destacam-se e de acordo com a literatura o tutor, aproveitando-se dos recursos disponíveis do ambiente virtual de aprendizagem, pode contribuir para a participação mais efetiva do aluno, aprendizagem significativa e com sua permanência no curso.

\section{REFERÊNCIAS}

CORTELAZZO, Iolanda Bueno de Camargo. Prática pedagógica, aprendizagem e avaliação em Educação a Distância. 1. ed. Curitiba: Ibpex, 2009.

CORTELAZZO, Iolanda Bueno de Camargo. Prática pedagógica, aprendizagem e avaliação em educação a distância. 3. ed. rev. e atal. Curitiba: Ibpex, 2013.

KENSKI, Vani Moreira. Tecnologias e ensino presencial e a distância. Campinas: Papirus, 2003.

MAIA, Carmem. MATTAR, João. ABC da EaD. 1. ed. São Paulo: Pearson Prentice Hall, 2007.

PATTO, Maria Helena Souza. Introdução à psicologia escolar. 4. ed. São Paulo: Casa do Psicólogo, 2010.

SALES, Patrícia de Andrade Oliveira. Evasão em Cursos a Distância: motivos relacionados às características do curso, do aluno e do contexto de estudo. 2009. 176f. Dissertação (Mestrado em Psicologia Social do trabalho e das Organizações) - Universidade de Brasília, Brasília: 2009. 